\title{
Rail vehicles recycling
}

\author{
A. Merkisz-Guranowska ${ }^{1}$, J. Merkisz $^{1}$, M. Jacyna ${ }^{2}$, \\ D. Pyza $^{2} \&$ H. Stawecka ${ }^{3}$ \\ ${ }^{1}$ Poznan University of Technology, Poland \\ ${ }^{2}$ Warsaw University of Technology, Poland \\ ${ }^{3}$ Rail Vehicles Institute TABOR, Poland
}

\begin{abstract}
Manufacturers and owners of rolling stock must allow for ecological aspects when conducting their activities. One of the possibilities of reducing the negative impact of rolling stock on the environment is the proper disposal of the end-oflife rolling stock. There are no regulations related to the recovery and recycling of rolling stock but owing to social responsibility and the possible economic benefits, we may find a plethora of examples of such actions. The paper describes the rules related to the end-of-life rolling stock treatment and the procedure of the disposal of rolling stock. The paper also presents the recovery rate of the applied materials and the recovery potential of selected rail vehicles. Keywords: rail vehicles recycling, end-of-life rolling stock, recovery rates, dismantling.
\end{abstract}

\section{Introduction}

The implementation of the policy of sustainable growth forces certain activities of the interested parties in all areas of life, transport and industry in particular. In the case of transport, this is particularly an improvement of the availability of transport services through a development of collective transport or green growth (increase in the supply of goods and passenger transport services without impact on the environment). A perfect response to the transporting challenges is the rail transport. The advantages of the rail transport from the point of view of the social benefits are as follows:

- increase in the accessibility to passenger transport for the poorest social groups, 
- greater safety of carriage compared to road transport,

- lower unit costs in the carriage of goods,

- lower greenhouse gases emission per unit of transported goods or per passenger compared to road or air transport,

- possibility of applying different sources of energy and its lower consumption per unit of transported goods or per passenger compared to road or air transport.

Despite the fact that rail transport realizes $11 \%$ of the carriage of goods (in thousands of kilometers) and $8 \%$ of the carriage of passengers (in thousands of kilometers) it is responsible for merely $0.6 \%$ of the emissions of greenhouse gases and $2 \%$ of the energy consumption in transport [1]. The number of transport fatalities in rail transport amounts to $0.1 \%$ in the carriage of passengers in the EU [1].

It is worth remembering that the environmental benefits should not only cover the stage of operation but also the other stages of the life cycle. This is the only approach that will ensure full competitiveness of rail transport. Hence, when designing and building new rolling stock, the manufacturers must take into account the entire life cycle of a vehicle that covers the production (design and building), operation (use and maintenance) and end of life (vehicle disposal).

The extent of the environmental impact in the last stage of the life cycle is related to the successful implementation of the $3 \mathrm{R}$ principle i.e. reduce, reuse and recycle. Already at the design stage of new rail vehicles and while developing production technologies, the amount of waste to be generated upon disposal needs to be minimized (reduce). At the stage of operation, a reuse of the greatest possible number of parts and subcomponents is assumed directly or following refurbishment (reuse). At the stage of disposal of a rail vehicle the greatest possible amount of waste needs to be recycled (recycle).

\section{The reasons for the development of recycling}

When comparing the rolling stock with vehicle fleet, the scale of the phenomenon is much smaller. On the other hand, the amount of waste generated by the rolling stock in relation to the number of the end-of-life rolling stock is much greater than in the case of motor vehicles.

The disposal of a single cargo railcar in terms of the weight of the obtained waste corresponds to the same of 16-20 passenger vehicles. From a disposal of a tram of the average length of $30 \mathrm{~m}$ we obtain waste equal to that of 36-42 passenger vehicles and a disposal of a passenger railcar $-48-57$ passenger vehicles. A disposal of a three-part electric multiple unit generates as much waste as 126 to 156 passenger vehicles.

Equally important to the disposal of the generated waste are the benefits we can have from the recycling of rail vehicles. These benefits include: reduction of the exploitation of resources, lower costs of production of recycled materials or the product image-related benefits (environment friendliness).

Thus, the reasons behind the growing need for effective end-of-life rail vehicles treatment can be summarized as follows: 
- energy efficiency issues,

- higher raw material costs,

- stricter landfill legislation and need for landfilled waste reduction,

- other environmental regulations related to producer's responsibility,

- customers' increasing product-related environmental requirements,

- the competitive advantage gained through eco friendly products.

\section{Legal regulations}

The recycling issues of rail vehicles have not been specified by the legislation on the EU level. Hence, there are no unified legal regulations related to the recycling or recovery rates or the obligations of manufacturers, owners or other entities related to the rolling stock disposal.

In some EU member states, local regulations indirectly force the rolling stock manufacturers to allow for the disposal problem by introducing this issue into the product technical documentation. For example in Poland, the Regulation of the Ministry of Infrastructure on the general technical conditions for railway vehicles exploitation obligates the manufacturer to include the recycling instructions in the last chapter of the Operation and Maintenance Manual (O\&M) [2]. The above regulation pertains to newly built and modernized rail vehicles, its assemblies and subassemblies. The description of the recycling principles in the O\&M in most cases remains on a very general level and only in few O\&Ms detailed information can be found on the material composition, the course of the disposal process (including dismantling) or the recycling and recovery rates [3].

On the supranational level, there are generally accepted documents that introduce standards related to the recycling of rail vehicles. In 2006, the Union of Railways (UIC) developed Leaflet 345 'Environmental specifications for new rolling stock' that defines the environmental requirements that must be taken into account at the design stage of the rail vehicles in the area of energy efficiency, noise, exhaust emissions and recycling [4]. According to the recommendations contained in it, already in the initial phase of the rail vehicle design the manufacturers should apply the REPID 2003 method allowing the incorporation of such aspects in the design process as: material recycling, effective resources management, avoidance of waste generation and obtainment of the highest possible recovery rate.

In 2012 the UIC submitted the Declaration on Sustainable Mobility and Transport as the international railway sector's Voluntary Commitment which obliges the partners to consider recycling as one of the key elements of their sustainable development strategy [5].

Unified recycling guidelines for the rolling stock were also developed in 2008 by Association of the European Rail Industry (UNIFE) gathering the manufacturers of rail vehicles. In this way product category rules (PCR) for rail vehicles were developed [6]. The basis for the guidelines is the ISO22628 standard for the automotive sector. Its regulations were adapted for the specificity of the rolling stock. Other applicable standards were also applied such as ISO14040 and ISO14044 - both related to the life cycle assessment. The PCR 
guidelines are to serve the purpose of preparation of the Environmental Product Declaration (EPD) as per the ISO14025 standard, thus constituting grounds for admittance of the rolling stock for use in the European Union. The details related to the method of calculating of the recovery and recycling rates were included in the document issued by UNIFE in January 2013 (document on recyclability and recoverability calculation method for railway rolling stock) [7].

It is worth stressing that none of the above-mentioned standards indicates the recovery and recycling rates for the rolling stock and none of them imposes methods of disposal of the end-of-life rolling stock, leaving the entities a choice between the energy recovery, part reuse and material recycling.

\section{The scope of recycling}

At the end of a vehicle life, it has to be properly disposed for further recovery. Whether recycling (i.e. treating the waste in a production process to obtain original substances or other substances and materials, excluding energy recovery) or energy recovery (combustion in order to use the energy contained in the waste) will be possible depends on the kind of material.

The used materials coming from rail vehicles are classified into the following seven categories, according to ISO 22628 [8]:

- metals,

- polymers, excluding elastomers - reinforced polymers, polymer compounds, all other undefined polymers, foam, sorted fractions, duromers,

- elastomers (rubbers),

- glass,

- fluids - oils, lubricants, all chemical fluids,

- modified organic natural materials (MONM), such as leather, wood, cardboard and cotton fleece,

- other, including components and/or materials for which the material composition cannot be ascertained (e.g. compounds, electronics and electrics).

Yet, due to the versatility of the applied materials, most importantly, due to various methods of their disposal, their more detailed specification seems reasonable (tab. 1). For the calculation of the recovery rate, maximum theoretical rates are assumed of the individual materials, based on the best available technologies. In practice, the recovery rates obtained when disposing end-of-life rail vehicles are lower. Due to the costs of labor, not all parts are dismantled and after shredding of a vehicle obtaining such a high recovery rate is impossible as is in the case of segregated materials.

Train carbodies are made largely of aluminum, steel or stainless steel - metals that are relatively easy to recycle. Steel is a recoverable material, largely due to the easiness of magnetic separation. Besides, the costs of steel production from recovered material are much lower than the production from iron ores. Aluminum, similarly to steel, does not lose its properties during recycling but the versatility of the alloys used to build vehicles makes the recycling process difficult. 
Table 1: Type of materials, their recovery rates and methods of recovery.

\begin{tabular}{|c|c|c|c|}
\hline Type of material & $\begin{array}{c}\text { Recovery rate } \\
\text { for calculation } \\
{[7]} \\
\end{array}$ & $\begin{array}{c}\text { Recovery } \\
\text { rate from } \\
\text { network }\end{array}$ & Recovery method \\
\hline $\begin{array}{l}\text { Ferrous metals - } \\
\text { Steel }\end{array}$ & $98 \%$ & $90-98 \%$ & Shredding and remelting \\
\hline $\begin{array}{l}\text { Ferrous metals - Cast } \\
\text { iron }\end{array}$ & $98 \%$ & $80-90 \%$ & Shredding and remelting \\
\hline $\begin{array}{l}\text { Non ferrous metals - } \\
\mathrm{Pb}\end{array}$ & $98 \%$ & $80-98 \%$ & $\begin{array}{l}\text { Dismantling, mechanical } \\
\text { separation and remelting } \\
\text { Shredding and remelting }\end{array}$ \\
\hline $\begin{array}{l}\text { Non ferrous metals - } \\
\text { Al }\end{array}$ & $98 \%$ & $80-95 \%$ & $\begin{array}{l}\text { Dismantling, mechanical } \\
\text { separation and remelting } \\
\text { Shredding and remelting }\end{array}$ \\
\hline $\begin{array}{l}\text { Non ferrous metals - } \\
\mathrm{Cu}, \mathrm{Zn}\end{array}$ & $98 \%$ & $60-80 \%$ & $\begin{array}{l}\text { Dismantling, mechanical } \\
\text { separation and remelting } \\
\text { Shredding and remelting }\end{array}$ \\
\hline $\begin{array}{l}\text { Polymers (excluding } \\
\text { elastomers) }\end{array}$ & $100 \%$ & $50-70 \%$ & $\begin{array}{l}\text { Dismantling, separation } \\
\text { and dedicated recycling } \\
\text { processes } \\
\text { Shredder light fraction } \\
\text { recycling } \\
\text { Incineration }\end{array}$ \\
\hline Elastomers & $100 \%$ & $50-70 \%$ & $\begin{array}{l}\text { Dedicated recycling } \\
\text { processes } \\
\text { Shredder light fraction } \\
\text { recycling } \\
\text { Incineration } \\
\end{array}$ \\
\hline Glass & $100 \%$ & $50-100 \%$ & Remelting \\
\hline Safety glass & $94 \%$ & $50-94 \%$ & Separation and remelting \\
\hline Oils & $100 \%$ & $50-100 \%$ & $\begin{array}{l}\text { Refining } \\
\text { Incineration }\end{array}$ \\
\hline $\begin{array}{l}\text { Other fluids } \\
\text { (lubricants, all } \\
\text { chemical fluids) }\end{array}$ & $83 \%$ & $50-80 \%$ & $\begin{array}{l}\text { Dedicated recycling } \\
\text { processes }\end{array}$ \\
\hline $\begin{array}{l}\text { Modified organic } \\
\text { natural materials }\end{array}$ & $100 \%$ & $50-70 \%$ & $\begin{array}{l}\text { Shredder light fraction } \\
\text { recycling }\end{array}$ \\
\hline $\begin{array}{l}\text { Carbon reinforced } \\
\text { polymers }\end{array}$ & $80 \%$ & $50-70 \%$ & $\begin{array}{l}\text { Dedicated recycling } \\
\text { processes }\end{array}$ \\
\hline $\begin{array}{l}\text { Electronic and } \\
\text { electric }\end{array}$ & $98 \%$ & $60-85 \%$ & $\begin{array}{l}\text { Sorting and dedicated } \\
\text { recycling processes }\end{array}$ \\
\hline
\end{tabular}

Cargo railcars are the easiest to recycle, as 60 to $80 \%$ of their mass is steel and cast iron. Passenger railcars are more difficult to recycle, multiple units in particular. Their material structure is varied. The greatest problem is novel technological solutions, particularly the application of composite materials such a carbon fibers (Carbon Fiber Reinforced Polymer) or glass fiber reinforced polymer. Currently, there are no technologies for easy and economically efficient recovery of these materials and their application becomes commonplace. Plastic 
is also a type of material difficult in recycling. It is characterized by a great versatility of application, relatively low costs of production and simple processing. Unfortunately, from the point of view of recycling, the difficulty is that most of them cannot be mixed with other types of plastic - each type of plastic has different chemical compositions (thus different melting or decomposition temperatures) and mechanical properties.

\section{Procedure for end-of-life vehicles}

The process of disposal of rail vehicles is similar to the process of disposal of motor vehicles but it must allow for the specificity of the sector (Figure 1).

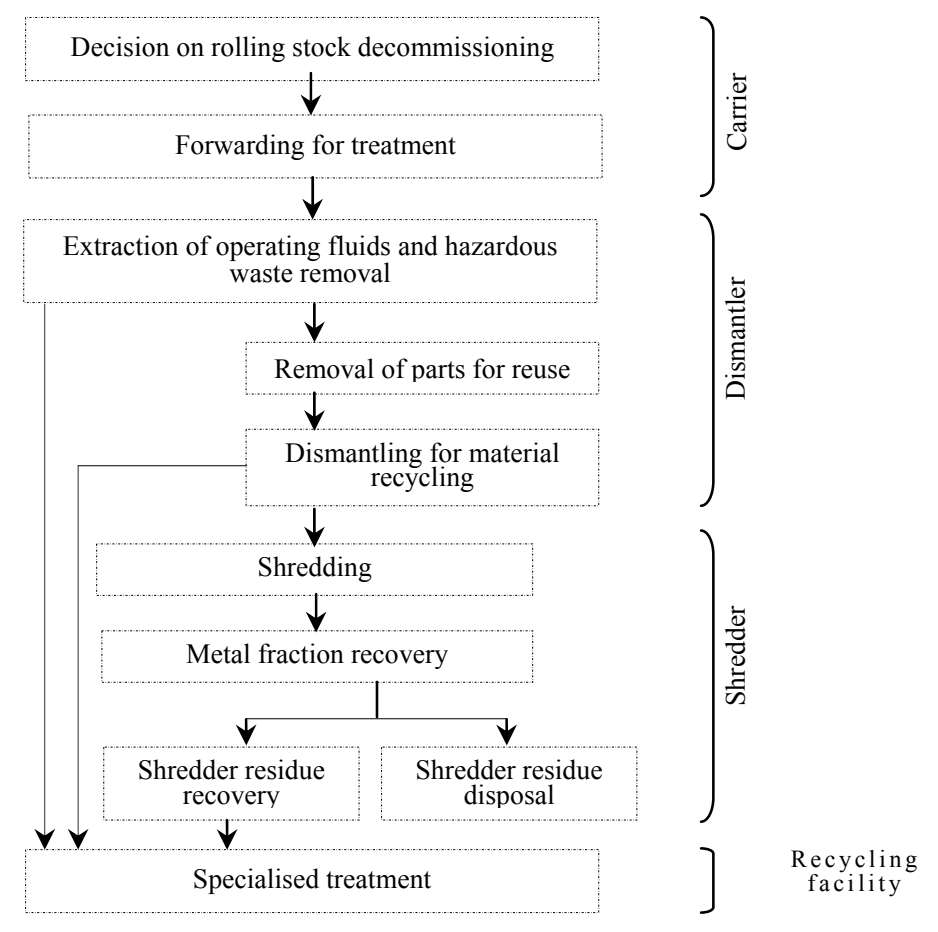

Figure 1: Recycling procedure for end-of-life rail vehicles.

Disposal of rail vehicles includes the following stages:

- forwarding the rolling stock for recycling,

- pre-treatment,

- dismantling,

- shredding,

- treatment of recovered materials and parts. 


\subsection{Forwarding the rolling stock for recycling}

The first step is making the decision on decommissioning of a vehicle and forwarding it to a place where its dismantling will be safe for the environment and whose recovery rate will be high. The life cycle of rail vehicles is approximately 30-40 years. The decommissioning decision may be made because of the rolling stock damage, repeated malfunctions, high repair costs, excessively high maintenance costs compared to new models available in the market as well as product obsolescence. European railway carriers decommission their rolling stock based on their own in-company regulations created based on many years of experience and legal environmental inclinations. Besides, (similarly to Deutsche Bahn, SNCF or PKP Cargo) they have an Integrated Management System and one of its elements is the Environmental Management System, whose primary aim is to continuously minimize environmental impacts. Hence, each carrier has a procedure of rolling stock decommissioning. The procedure includes the following elements:

- reporting of rolling stock for decommissioning,

- collective inspection of the reported rolling stock,

- decision on ending the vehicle's life,

- forwarding railcar/s for treatment,

- dismantling for recycling,

- financial settlement of the disposal.

The said steps determine the procedure of recycling from the point of view of the carrier, while the proper recycling process starts from the moment when the rolling stock is forwarded to the dismantler and ends with a physical disposal of a rail vehicle (the vehicle becomes waste as of the moment of decommissioning.) The end-of-life rolling stock may be forwarded to the dismantler that is part of the carrier's infrastructure (operating within the organizational structure of the company) or to a contractual entity. It also happens that the rolling stock is dismantled at the location where it is stored. This, however, should be avoided whenever possible.

\subsection{Pre-treatment}

Similarly to end-of-life vehicles, end-of-life rolling stock is treated as hazardous waste. Thus, before dismantling it should be prepared in such a way that it remains safe for human health and the environment at further stages of the recycling process. The stage of initial treatment includes vehicle draining and removing hazardous waste and pollutants. Operating fluids (oils, brake fluids, antifreeze) removed from the vehicle should be stored in separate containers and then forwarded to specialized facilities responsible for material recycling or energy recovery (oils). Parts or components that are to be reused as spares are not drained. Besides, due to health and environmental hazards, batteries, gases, explosives, fire extinguishers, braking sand, greases and catalytic capacitors must be removed. Subsequently, they too are forwarded to specialized recycling facilities. 


\subsection{Dismantling}

In the dismantling process, parts and subcomponents that can be further used or recycled are removed. In the first place, parts and subcomponents that are to be further used are retrieved. These subcomponents are: bogies, bogie frames, wheel sets, couplings, buffers, springs, control valves, brake systems, doors. Some parts can be directly used in other rail vehicles and some will require refurbishment to regain the original operating parameters. All parts for reuse are to be removed with proper care to avoid damage and must go through an inspection determining the extent of refurbishment and possible admittance for use.

Then the rest of the elements are dismantled for further material recycling such as seats, glazing, wire harnesses, electronic parts, flooring, HVAC units etc. Railcar parts should be marked or, alternatively, the dismantlers should have access to the documentation prepared by the rolling stock manufacturer so that the material composition of a given part could be identified before further treatment. The rolling stock manufacturers must thus collect such information from their suppliers and create databases. At this stage, the dismantling time is the key factor (the longer the time the less cost effective the entire process), hence the manufacturers should apply easily detachable connections that reduce time consuming dismantling work.

The guidelines and rules that are to be adhered to when dismantling rail vehicles are as follows:

- parts and materials for which there is no recycling technology or the technology is locally unavailable are not dismantled,

- only the elements that can be identified in terms of material composition are dismantled,

- parts whose dismantling is particularly time-consuming are not dismantled,

- only those parts and subcomponents to which there is easy access are dismantled (except parts that are of high value).

All elements that are not dismantled at this stage will most likely be recovered at the next stage, during scrapping. Yet, the greater the extent of the dismantling, the easier it is to separate the individual material fractions, the more effective the recycling process and the higher the recycling rate. With the aim of maximizing the recovery rate the highest possible number of elements should be dismantled at this stage, but it is a costly process and its extent must usually be economically justified.

The elements and subcomponents removed during dismantling are forwarded to specialized recycling facilities where they are separated, sorted and undergo a proper recycling process.

\subsection{Shredding}

Upon dismantling of the elements for further use and material recycling, the vehicle is forwarded to the industrial shredder for scrapping. Prior to forwarding 
of the waste to the shredder, it is pressed to reduce the space needed for transport, which reduces the costs of carriage. The reduction of volume is realized by a mechanical press. Following this, the packed materials are grinded into small pieces for further treatment.

The main task of an industrial shredder is the recovery of the metal fraction. Upon shredding the waste is segregated into the following fractions [9]:

- ferrous metals: steel and irons,

- non-ferrous metals, mainly aluminum, copper, zinc, magnesium,

- light shredder residue - a mix of different materials and substances such as plastics (including foams and textiles), fibers (wood, textiles), glass and ceramics, elastomers, remaining minerals (soil, sand) and residue (rust, dust, paint coatings).

Ferrous and non-ferrous metals are almost fully treated to become recycled materials. Shredder residue may be further segregated for reuse or partly combusted with energy recovery due to its high calorific value. Approximately $50 \%$ of the light shredder residue contains a combustible fraction that can be thermally treated. The treatment of shredder residue is an alternative solution to deep dismantling at the previous stage but it requires fitting proper segregating equipment at the industrial shredders and recipients of this type of waste must be present in the market.

Even though there are technologies that enable sorting and using up to two thirds of the mass of the shredder residue [10] due to their rare application in practice $67 \%$ of the remains after shredding is landfilled. In some countries like Poland, shredder residue is not treated at all and it is all forwarded to the landfill.

\subsection{Treatment of recovered materials and parts}

All dismantled elements and components at the stage of initial and proper dismantling (except parts and subcomponents that are good for direct reuse) are forwarded to specialized recycling facilities where they are treated with the use of available technologies. The dedicated recycling must be applied to: batteries, all elements containing hazardous substances, oils and other operating fluids, parts for refurbishment, electronics, electrics and plastics elements. Similarly, the materials separated in the shredding process are forwarded to steelworks or nonferrous metal recycling facilities. The separated fractions of the shredder residue are directly used in the industry (polymer granulate can be used in blast furnace, fibers and foams in sewage sludge conditioning).

The key factor related to the development of recycling and the extent and profitability is the collaboration with respective industry partners in the value added chain. They must ensure and implement technologies of material recycling. Besides, there must be a market for the recycled materials or recovered fractions. Without the above, the process of waste treatment will not bring the expected environmental results and the recovery will be applied only to this type of waste that is characterized by a high demand. 


\section{Recycling-friendly rolling stock}

Reaching a 95\% recovery rate for new cargo railcars was not a great difficulty even in the past, contrary to multiple units and passenger railcars. The first multiple unit that ensured a reuse and recovery of materials on the level of $95 \%$ of the vehicle weight was a low-floor unit Coradia Nordic (originally marketed as Coradia Lirex) supplied in 2005 by Alstom for the commuter services in the Stockholm area [11]. Currently, an increasing number of newly designed vehicles guarantee a high recovery rate. Another product by Alstom is a good example - Pendolino trains to be delivered by 2015 to a Swiss carrier - SBB. Trams manufactured by Alstom have even higher recovery rates. The Citadis model supplied to a French city of Le Havre, despite the use of composite materials guaranteed up to $98 \%$ of the recovery rate [12]. In 2012 Alstom created a consortium of Alstom Transport, Hiolle Industries, LME Trith, Ramery Environnement and the Vitamine T Group whose aim is the recycling of the rolling stock. The first end-of-life vehicles of the Paris transit operator (RATP) will be the experimental vehicles to set standard procedures and future objectives in recycling.

Bombardier Transportation has also joined the group of manufacturers offering vehicles fully adapted to the needs of rolling stock recycling and recovery. Light rail vehicles Bombardier Flexity Swift have 92\% recycling rate and $98 \%$ recovery rate and the average recovery rate for the entire rolling stock manufactured by the company is over $95 \%$ [13]. Bombardier has also adopted a resolution that all manufactured vehicles will aim at a $100 \%$ recovery rate. This will be facilitated by the minimization of use of hazardous substances and materials along with the application of recycling-friendly materials (aluminum and steel) as well as avoidance of combining of an excess number of materials.

The manufacturers are frequently inspired or supported by the expectations of the transport organizers. An example of the most sustainable rail transport system is the subway network in Norwegian Oslo. The guidelines for dismantling and recycling developed by Siemens already on the design stage are now a regular element of a system of subway servicing. The subway rolling stock is characterized by an almost $95 \%$ recovery rate [10]. $85 \%$ of the mass is subject to recycling and another $10 \%$ is combusted with energy recovery. $60 \%$ of aluminum and $40 \%$ of steel used for the construction of the rolling stock comes from recycling.

The experience gained by Siemens in Norwegian Oslo was then used for designing and manufacturing Inspiro railcars for the Warsaw subway that were introduced in 2013. The materials used for the production of a 6-unit train of the gross weight of 158.2 ton can be recovered in the recycling process in $94.8 \%$. Only $5.2 \%$ of the total mass of the train is waste that has to be landfilled and cannot in any way be reused. The Inspiro trains are built in compliance with the ISO14021 ecological standard. Numerous measures were undertaken to reduce the weight of the Inspiro [14]. The front end of the cars alone, which houses the couplings, weighs 500 kilograms less than before. Its design is based on the use of light aluminum profiles. Certain components in the cars themselves were 
made as multifunctional as possible - for example, parts of the ceiling also serve as cable ducts. In a further effort to reduce weight, air ducts are made of light textiles rather than the metal previously used, while a new type of corkaluminum floor weighs 30 percent less than before, acts as a noise dampener, and also provides better heat insulation.

The forecasted process of disposal upon decommissioning is to be performed in the following order [14]:

- At the initial stage of dismantling, all hazardous (for humans and the environment) and explosive materials must be removed. Such materials as mineral oils (transmissions, compressors, emergency doors), coolants, batteries and fire extinguishers must be forwarded for recovery. The forecasted mass of the waste at this stage is $0.75 \%$ of the total vehicle mass.

- The second stage assumes dismantling of parts and elements that are separated from the vehicle. In this process, parts and elements of the mass of $30.92 \%$ of the total mass of the train are recovered. These elements include: front panels, glazing, head and wall liners, rear wall lining, thermal insulation, motorman and passenger seats, engines, motors and gearsets, rubber-metal components, electrical harnesses, LED lighting, auxiliary inverters, motorman instrument clusters (including electrical equipment), compact roof ventilation, filtering and heating equipment for the passenger compartment, air ducts, door flaps, door driving units, P.A. systems, air compressors, air modules, gangways, couplings and cable channels.

- The third stage is shredding of the main part of the vehicles and its vital subassemblies. In this process, ferrous and non-ferrous metals are recycled and their mass is $68.33 \%$ of the total mass of the train.

\section{Conclusions}

In the area of rail vehicle recycling, despite the fact that there is no precise legislation in this matter, rolling stock manufacturers and its users should support the European policy on waste management. The reference is the standards and requirements applicable for motor vehicles. Due to a lack of legislation for the rolling stock, there are no limitations as to the scope of application of the individual types of disposal (recycling, energy recovery) as opposed to the automotive sector where energy recovery is limited.

Thanks to the implementation of a voluntary policy, modern vehicles are ready for their end-of-life recycling. The recovery of raw materials through recycling is a sustainable type of creation of value. A wide variety of materials can be re-processed and then secondary raw materials can be re-used. The rolling stock manufacturers, when designing a vehicle, allow for the necessity of their recycling, which is manifested through the application of recyclable materials, material marking and proper material combinations. This is to enable quick dismantling and separation of the material fractions in the future. The rolling stock recovery rate may reach up to $95 \%$, similarly to motor vehicles. The actual recovery rate, however, will depend on many factors such as: the existence of infrastructure of specialized material recycling facilities, 
accessibility to recovery technologies, new types of materials, demand for recycled materials and refurbished parts, legal regulations forcing the business entities to achieve required recovery rates and the expectations and environment protection policies applied by the rolling stock owners and users.

\section{References}

[1] European Commission, EU Transport in figures, Statistical pocketbook, Luxembourg 2013.

[2] The Ministry of Infrastructure's Regulation of 12 October 2005 on the general technical conditions for railway vehicles' exploitation, Dziennik Ustaw no. 212, document 1771, Warsaw 2005.

[3] Informational materials of Rail Vehicles Institute TABOR. Retrieved December 2013.

[4] UIC International Union of Railways, Leaflet UIC 345 Environmental Specifications for new rolling Stock, 2006.

[5] UIC \& United Nations Conference on Sustainable development RIO+20, Rio de Janeiro, 2012.

[6] International EPD Consortium, "Product category rules (PCR) for preparing an environmental product declaration (EPD) for rail vehicles", UNCPC Code: 495, 2009.

[7] UNIFE Association of the European Rail Industry, Sustainable Transport Committee, "Recyclability and Recoverability Calculation Method Railway Rolling Stock", Brussels 2013.

[8] International Standard, ISO 22628 - Road vehicles - Recyclability and recoverability - Calculation method, 2002.

[9] Hjelmar, O., Shredder Waste Characteristics and Management Options, CISA Publisher, Horsholm, 2009.

[10] Krinke, S., Bossdorf-Zimmer, B., Goldmann, D., The Volkswagen-SiCon Process: Eco-efficient solution for future end-of-life vehicle treatment, Proceedings LCE2006, Wolfsburg, pp. 359-364, 2006.

[11] Roden A., Alstom unveils new train for Stockholm commuters, International Railway Journal, vol. 45, issue 7, p. 32, 2005.

[12] Alstom, Official website, www.alstom.com, Retrieved October 2013.

[13] Bombardier Transportation, Official website, csr.bombardier.com, Retrieved October 2013.

[14] Siemens, Official website, www.siemens.com, Retrieved October 2013. 